\title{
Clinical effect of two anterior approaches to adjacent two-segment cervical spondylotic myelopathy.
}

\author{
Yongning Li, Lin Gou, Yiguang Bai, Xuwei Luo, Wei Li*, Liang Li \\ Department of Spinal Surgery, Nanchong Central Hospital, the Second Clinical College of North Sichuan Medical \\ College, Nanchong, Sichuan, PR China
}

\begin{abstract}
Objective: This paper discusses the clinical effects of two anterior approaches to adjacent two-segment Cervical Spondylotic Myelopathy (CSM).

Methods: A total of 108 patients with adjacent two-segment CSM who were admitted to our hospital from November 2015 to January 2017 were selected and divided randomly into control and observation groups according to different anterior approaches. The control group (46 cases) used single-segment Anterior Centrum Corpectomy Fusion (ACCF), whereas the observation group (62 cases) adopted twosegment Anterior Cervical Decompression and Fusion (ACDF). Indexes in perioperative period, visual analog scale score, JOA score, height of fused segment, and cervical curvature of the two groups were observed and compared.

Results: The observation group achieves a significant increase in the amount of bleeding and time of operation compared with the control group $(\mathbf{P}<0.05)$. No significant difference is found between the two groups in terms of length of stay $(\mathbf{P}>0.05)$. The observation group fails to achieve significant improvement compared with the control group in terms of VAS and JOA scores $(P>0.05)$. By contrast, the observation group shows significant improvements in the height of fused segment and cervical curvature than the control group $(\mathrm{P}<\mathbf{0 . 0 5})$.

Conclusion: Reasonable selection of ACDF in clinical treatment of adjacent two-segment CSM can reduce the amount of bleeding during the operation significantly, thereby improving the cervical curvature and height of fused segment.
\end{abstract}

Keywords: Adjacent two-segment CSM, ACCF, ACDF, Clinical effect.

Accepted on December 7, 2017

\section{Introduction}

Cervical Spondylotic Myelopathy (CSM) demonstrates high probability for causing quadriplegia in patients [1]. The probability for patients to develop adjacent two-segment CSM is increasing dramatically given the intensified aging trend and degenerative changes [2]. Anterior Centrum Corpectomy Fusion (ACCF) and Anterior Cervical Decompression and Fusion (ACDF) are two major clinical treatments for patients with adjacent two-segment CSM [3]. This study aims to determine the optimal treatment to adjacent two-segment CSM. ACDF has been verified to exhibit higher clinical application value than ACCF.

\section{Information and Method}

\section{General information}

In this study, 108 patients with adjacent two-segment CSM who were admitted to our hospital from November 2015 to January 2017 were selected and divided randomly into control and observation groups according to different anterior approaches. The control group (46 cases) included 26 males and 20 females aged $49-82(59.03 \pm 8.15 \mathrm{y})$ on average. The observation group (62 cases) included 38 males and 24 females aged 51-83 (59.05 $\pm 8.16 \mathrm{y})$ on average. Both groups demonstrated significant differences in gender and age $(\mathrm{P}>0.05)$.

\section{Selection criteria}

Symptoms and signs in all patients with adjacent two-segment CSM were observed. CT, cervical vertebra X-ray, and MRI examinations were performed [4]. Thus, diseases were diagnosed effectively. The lesion segment of the patients was limited to $\mathrm{C} 3 / 4$ and $\mathrm{C} 6 / 7$. A three-month standard conservative treatment was applied to patients but failed to achieve the clinical effect.

\section{Exclusion criteria}

Patients with secondary clinical operation; underwent $\mathrm{C} 7$ corpectomy; with imperfect imaging data; with less than 12 months of follow-up; with infection, trauma, and tumor; 
cervical vertebra malformation; and developmental spinal stenosis were excluded [5].

\section{Methods}

Preoperative preparation: Tracheal passage and esophageal training must be performed before the operation of patients with adjacent two-segment CSM to prevent laryngeal edema and laryngismus [6]. In addition, reasonable urine and defecation training in bed shall be implemented to prevent difficult micturition and defecation after the operation, which may induce difficult nursing. Urinary tract infection caused by catheter intervention shall be strictly prevented.

Reasonable operation: General anesthesia and supine position during the operation were used on all patients with adjacent two-segment CSM. An operative incision was made on the right side of the neck (4 cm long) to expose the anterior centrum [7]. A C-type arm X-ray machine was used during the operation for fluoroscopy and identification of location. The space between the carotid and internal peritoneal sheaths was determined. A distractor was used in the spaces between the segments for effective expansion, which is conducive to surgical operation significantly.

For ACDF, pituitary rongeur tip was inserted accurately to expand the space between segments. Lesion nucleus pulposus was eliminated several times. Subsequently, a curette was used to eliminate residual nucleus pulposus and cartilage plate at vertebral posterior. The autodecompression bone after pressure reduction was inserted accurately by using PEEK fusion cage, and the space between the corresponding segments was inbuilt. The space of another segment was treated similarly. Finally, two segments were fixed by using a cervical spine-locking plate.

For ACCF, the space between the head and tail of the intervertebral space in the damaged segment was located accurately. Damaged intervertebral disc tissues were removed effectively. Separation treatment was performed according to the lesion segment and posterior longitudinal ligament space. Hyperplasia osteophyte at the posterior part was treated. Then, the expansion was eliminated by using an impact rongeur in the pressure relief groove. Stealth decompression operation was conducted after the posterior part was treated by using a vertebral rongeur. Subsequently, the autodecompression bone was inserted accurately in the titanium mesh, and the corresponding space was inbuilt. Finally, two segments were fixed by a cervical spine-locking plate.

Reasonable implementation of postoperative treatment: Antibiotics were administered for infection prevention after the operation. The normal colloid osmotic pressure of patients was assured completely [8]. Disease conditions were closely monitored, and corresponding treatments were provided. Drainage was observed carefully at 24 and $48 \mathrm{~h}$ after the operation. The drainage tube was eliminated properly. The patients were protected by a cervical gear for three months until bone graft fusion.
Curative effect judgment and observation indexes: The amount of bleeding, Length of Stay (LOS), and time of operation in both groups were compared. Neurological functions of both groups before and after the operation were evaluated by using their JOA scores. Pain was assessed by using a Visual Analog Scale (VAS).

Images before the operation, $3 \mathrm{~d}$ after the operation, and on the final follow-up were captured. The cervical curvature and height of fused segment were measured through X-ray imaging of the neural site.

\section{Statistical analysis}

The surgical results of all patients with adjacent two-segment CSM were analysed by SPSS20.0. Measurement data (indexes during the perioperative period) were expressed in $\bar{x} \pm s$ and examined through a t-test. $\mathrm{P}<0.05$ indicates statistically significant difference.

\section{Results}

\section{Indexes during perioperative period}

The amount of bleeding and time of operation in both groups were compared. The observation group showed significant improvement compared with the control group $(\mathrm{P}<0.05)$. However, no significant difference was found between the two groups in terms of $\operatorname{LOS}(\mathrm{P}>0.05)$ (Table 1$)$.

Table 1. Comparison of indexes between the two groups during the perioperative period $(\bar{x} \pm s)$.

\begin{tabular}{lllll}
\hline Groups & $\mathbf{n}$ & LOS $(\mathbf{d})$ & $\begin{array}{l}\text { Amount of } \\
\text { bleeding }(\mathrm{ml})\end{array}$ & Time of operation (min) \\
\hline Observation & 62 & $9.12 \pm 0.65$ & $175.39 \pm 12.15$ & $64.53 \pm 10.21$ \\
\hline Control & 46 & $9.21 \pm 0.88$ & $201.32 \pm 80.39$ & $70.02 \pm 11.13$ \\
\hline $\mathrm{t}$ & & 0.6115 & 2.5054 & 2.6589 \\
\hline $\mathrm{P}$ & $>0.05$ & $<0.05$ & $<0.05$ \\
\hline
\end{tabular}

\section{VAS and JOA scores}

The observation group failed to achieve significant improvement in terms of the VAS and JOA scores compared with the control group $(\mathrm{P}>0.05)$ (Table 2).

Table 2. Comparison of VAS and JOA scores between the two groups $(\bar{x} \pm s$, scores $)$.

\begin{tabular}{llllll}
\hline Groups & $\mathbf{n}$ & VAS & \multicolumn{3}{l}{ JOA } \\
\cline { 2 - 6 } & & Before & After & Before & After \\
\hline Observation & 62 & $6.49 \pm 1.45$ & $2.99 \pm 1.29$ & $13.07 \pm 0.82$ & $15.46 \pm 1.07$ \\
\hline Control & 46 & $5.97 \pm 2.71$ & $2.97 \pm 0.79$ & $12.99 \pm 0.79$ & $15.29 \pm 0.82$ \\
\hline $\mathrm{t}$ & & 1.2845 & 0.0929 & 0.5091 & 0.8989 \\
\hline $\mathrm{P}$ & $>0.05$ & $>0.05$ & $>0.05$ & $>0.05$ \\
\hline
\end{tabular}




\section{Height of fused segment}

The observation groups presented outstanding improvements in terms of the height of fused segment compared with the control group $(\mathrm{P}<0.05)$ (Table 3$)$.

Table 3. Comparison of the height of fused segment between the two groups $(\bar{x} \pm s, m m)$.

\begin{tabular}{lllll}
\hline Groups & $\mathbf{n}$ & Before & $\begin{array}{l}\text { 3 d after the } \\
\text { operation }\end{array}$ & Final follow-up \\
\hline Observation & 62 & $54.59 \pm 2.63$ & $57.39 \pm 3.33$ & $56.25 \pm 2.12$ \\
\hline Control & 46 & $54.62 \pm 2.61$ & $55.29 \pm 3.19$ & $55.05 \pm 2.39$ \\
\hline $\mathrm{t}$ & & 0.0588 & 3.2988 & 2.7546 \\
\hline $\mathrm{P}$ & $>0.05$ & $<0.05$ & $<0.05$ \\
\hline
\end{tabular}

\section{Cervical curvature}

The observation groups had a remarkable improvement in terms of cervical curvature compared with the control group $(\mathrm{P}<0.05)$ (Table 4).

Table 4. Comparison of the cervical curvature between the two groups $\left(\bar{x} \pm s,{ }^{\circ}\right)$.

\begin{tabular}{lllll}
\hline Groups & $\mathbf{n}$ & Before & $\begin{array}{l}\text { 3 d after } \\
\text { operation }\end{array}$ & the Final follow-up \\
\hline Observation & 62 & $5.32 \pm 3.55$ & $9.31 \pm 2.63$ & $8.32 \pm 2.41$ \\
\hline Control & 46 & $5.51 \pm 3.52$ & $7.05 \pm 2.85$ & $6.03 \pm 1.62$ \\
\hline $\mathrm{t}$ & & 0.2760 & 4.2610 & 5.5744 \\
\hline $\mathrm{P}$ & $>0.05$ & $<0.05$ & $<0.05$ \\
\hline
\end{tabular}

\section{Discussion}

ACDF can not only reduce the amount of bleeding significantly during the clinical treatment of patients with adjacent two-segment CSM but also improve the cervical curvature and height of fused segment dramatically [9].

This study found that the observation group achieved significant improvements in terms of the amount of bleeding and time of operation compared with the control group $(\mathrm{P}<0.05)$. The LOS between the two groups was not statistically significant $(\mathrm{P}>0.05)$. The observation group failed to achieve significant improvements in terms of VAS and JOA scores compared with the control group $(\mathrm{P}>0.05)$. The observation groups presented outstanding improvements in terms of the height of fused segment and cervical curvature compared with the control group $(\mathrm{P}<0.05)$. These results validated the clinical application value of ACDF in improving its comprehensive therapeutic effect on patients with adjacent two-segment CSM comprehensively [10].

\section{Conclusion}

Reasonable selection of ACDF in the clinical treatment of adjacent two-segment CSM can sufficiently ensure the comprehensive therapeutic effect, prognosis ability, and living ability of patients.

\section{References}

1. Cao JM, Zhang JT, Yang DL, Yang YP, Xia HH, Yang L. Imaging factors that distinguish between patients with asymptomatic and symptomatic cervical spondylotic myelopathy with mild to moderate cervical spinal cord compression. Med Sci Monit 2017; 23: 4901-4908.

2. Polat Y. Effects of CoQ10 and zinc supplemented trainings upon some blood parameters. Biomed Res India 2017; 28: 4287-4293.

3. Zhou H, Liu Z, Wang S, Pan S, Yan M, Zhang F, Sun Y. Laminoplasty with lateral mass screw fixation for cervical spondylotic myelopathy in patients with athetoid cerebral palsy. Medicine (Baltimore) 2016; 95: 5033.

4. Li L, Cui W, Huang CP, Zhao LY. Albumin affects the inhibition of UDP-glucuronosyltransferase (UGT) 2B7 by cervical carcinoma treatment drug andrographolide. Lat Am J Pharm 2015; 34: 1680-1683.

5. Fei Q, Li J, N Su, Wang B, Li D, Meng H, Wang Q, Lin J, Ma Z, Yang Y. Comparison between anterior cervical discectomy with fusion and anterior cervical corpectomy with fusion for the treatment of cervical spondylotic myelopathy: a meta-analysis. Ther Clin Risk Manag 2015; 11: 1707-1718.

6. Forati S, Yaghmaii B, Allah-Verdi B. The effect of early feeding after enema reduction of intussusception in order to investigate the rate of recurrence and side effects of reduction. Biomed Res India 2017; 28: 5642-5645.

7. Nishida N, Kato Y, Imajo Y, Kawano S, Taguchi T. Biomechanical analysis of cervical spondylotic myelopathy: The influence of dynamic factors and morphometry of the spinal cord. J Spinal Cord Med 2012; $35 ; 256-261$.

8. Lu W, Jia G, Meng X, Zhao C, Ni Y. Baicalein inhibits growth of cervical carcinoma via inducing apoptosis of tumor cells in vivo. Lat Am J Pharm 2013; 32: 31-36.

9. Dong F, Shen C, Jiang S, Zhang R, Song P, Yu Y, Wang S, Li X, Zhao G, Ding C. Measurement of volume-occupying rate of cervical spinal canal and its role in cervical spondylotic myelopathy. Eur Spine J 2013; 22: 1152-1157.

10. Connolly KP, Kamath AF. Direct anterior total hip arthroplasty: Comparative outcomes and contemporary results. World J Orthop 2016; 7: 94-101. 


\section{"Correspondence to}

Wei Li

Department of Spinal Surgery

Nanchong Central Hospital

The Second Clinical College of North Sichuan Medical College

PR China 